\title{
Numerical simulation and optimization of Sleipner carbon sequestration project
}

\author{
Zheming Zhang", Ramesh Agarwal \\ Department of mechanical engineering and materials science, Washington university in St Louis \\ *Corresponding author E-mail:
}

Copyright (C) 2014 Zheming Zhang and Ramesh Agarwal. This is an open access article distributed under the Creative Commons Attribution License, which permits unrestricted use, distribution, and reproduction in any medium, provided the original work is properly cited.

\begin{abstract}
The capability of accurate numerical simulation and optimization is needed as the technology of geological carbon sequestration (GCS) advances. It can provide quick information for preliminary design of a GCS project. The simulation and optimization results can provide better understanding of the nature of GCS and the uncertainties associated with it and therefore can provide guidelines and the development of best practices for its deployment. In this paper, first the satisfactory history-matching of the Sleipner GCS project is achieved by using the TOUGH 2 simulation package. Next, the reservoir engineering technique known as water-alternating-gas (WAG) is applied to the model of the Utsira formation and optimization studies are conducted to determine the optimal WAG operation using the recently developed genetic algorithm based simulation/optimization code GA-TOUGH2. Results of WAG optimization suggest that in situ $\mathrm{CO}_{2}$ footprint reduction and $\mathrm{CO}_{2}$ dissolution acceleration can be achieved while minimizing the water usage.
\end{abstract}

Keywords: Carbon sequestration, numerical simulation, optimization, Sleipner project, water-alternating-gas injection.

\section{Introduction}

Among all possible carbon sinks for sequestration, deep saline aquifer geological carbon sequestration (SAGCS) appears to be quite attractive because of its huge capacity for sequestration and its relatively smaller environmental risk [1]. However, the large spatial extent and time duration of $\mathrm{CO}_{2}$ plume migration after injection makes the study of GCS very difficult for laboratory scale experiment and costly using field tests. With proper modeling of the storage formation and ground water transportation, numerical simulation is capable of providing accurate enough analysis for quick estimation of reservoir performance at considerably lower cost. It also brings significant flexibility for investigating the effect of various injection parameters, e.g. injection rate and its duration, on $\mathrm{CO}_{2}$ storage efficiency and plume migration in a given reservoir. Another important advantage of numerical simulation is that it makes it possible to perform optimization studies of these injection parameters for achieving the highest possible storage efficiency with minimum plume migration. Such an optimization capability can aid in successful implementation of GCS on industrial scale.

\section{Methodology}

In this paper, numerical simulations of Sleipner saline aquifer geological carbon sequestration (SAGCS) project are conducted using the multi-phase, multi-component groundwater transport solver TOUGH2, which has been widely used worldwide to determine a-priori the $\mathrm{CO}_{2}$ storage capacity of a saline aquifer and for risk assessment [2], [3], [4]. The governing equations of mass/energy transportation and numerical representations of the formation properties have been well explained in the TOUGH2 User's Guide [5], [6], [7]. Optimizations are performed using a genetic algorithm (GA). GA belongs to a class of optimization techniques that are inspired by the biological evolution [8], [9]. The algorithm begins with a set (identified as "generations") of vectors (identified as "individuals"). The individuals from one generation are used to create a new generation of individuals, which is supposed to be better than the previous generation. Individuals used to form the new individuals (identified as "offspring") for the succeeding generation are 
selected according to their function value of satisfying a certain criteria (identified as the "fitness function"). This process is iterated to create the best individuals for each successive generation according to certain pre-defined criteria. Detailed explanations of the GA can be found in Goldberg's book [9] and our previous work [10].

To realize the capability of numerical simulation and optimization for SAGCS, the GA optimizer is implemented into the TOUGH2 solver to obtain a simulation-optimization integrated computer program. Additional modules for pre- and post-simulation process are introduced to enable the data sharing between GA and TOUGH2. A schematic of the GATOUGH 2 architecture and data flow is presented in Figure 1. More details of the code integration can be found in our previous work [10], [11].

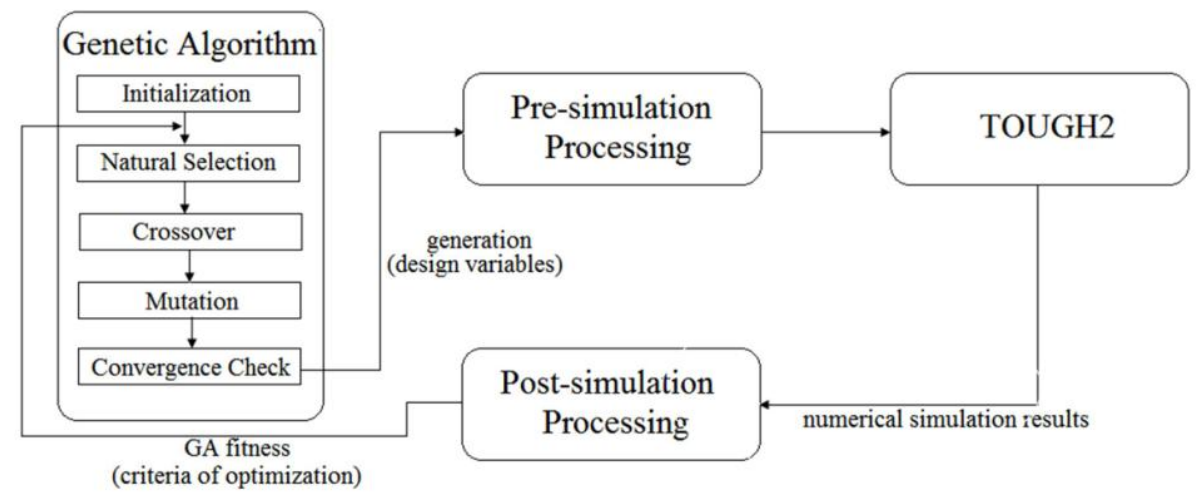

Fig 1: Schematic of GA-TOUGH2 integrated program [10]

\subsection{Optimization of $\mathrm{CO}_{2}$ plume migration for water-alternating-gas (WAG) injection scheme}

Reservoir engineering technique known as water-alternating-gas (WAG) scheme has been considered for SAGCS with generic saline aquifers to improve the sequestration efficiency defined as the pore space utilization, although an additional injection of water with $\mathrm{CO}_{2}$ will inevitably increase the cost [10], [11], [12]. GA-TOUGH2 is employed to determine the optimal WAG operation for maximum $\mathrm{CO}_{2}$ sequestration efficiency while minimizing the water usage. Inspired by the practice in oil industry, the potential of WAG operation for GCS has been surmised by several investigators that intermittent injection of $\mathrm{CO}_{2}$ and water could lead to better $\mathrm{CO}_{2}$ storage efficiency by reducing the migration of $\mathrm{CO}_{2}$ plume [13], [14], enhancing the residual trapping [15], [16], and accelerating the $\mathrm{CO}_{2}$ dissolution [17], [18].

Improved (reduced) $\mathrm{CO}_{2}$-brine mobility ratio and accelerated $\mathrm{CO}_{2}$ dissolution are the two important characteristics that motivate the adoption of WAG operation to SAGCS. In multiphase flow, the non-wetting phase to wetting phase mobility ratio is defined as:

$M=\frac{m_{n}}{m_{w}}=\frac{\mu_{w} \cdot k_{m}}{\mu_{n} \cdot k_{m}}$

where $\mu_{w}$ is the wetting phase viscosity, $k_{r w}$ is the wetting phase relative permeability, $\mu_{n w}$ is the non-wetting phase viscosity, and $k_{r n}$ is the non-wetting phase relative permeability.

In the context of SAGCS, the pre-existing brine is considered as wetting phase and injected supercritical $\mathrm{CO}_{2}$ is considered as non-wetting phase. If the intermittent $\mathrm{CO}_{2}$-water injection is treated as quasi-mixture entering the aquifer, it will effectively bring down the mobility ratio compared to that of pure $\mathrm{CO}_{2}$ injection. With the mobility ratio approaching unity, it is expected that (1) the displacement of the reservoir fluid will become more stable avoiding the formation of water/gas fingers and (2) the speed of buoyancy-driven $\mathrm{CO}_{2}$ migration will be reduced [13]. Since the buoyancy-driven upward motion is the main cause of the excessive lateral migration of in situ $\mathrm{CO}_{2}$, it implies that in situ $\mathrm{CO}_{2}$ will rise and spread slowly by reducing the mobility ratio resulting into smaller environmental footprint.

Another key aspect of WAG operation is the enhanced $\mathrm{CO}_{2}$ dissolution. In literature, reservoir engineering techniques of injecting brine into the aquifer after the completion of $\mathrm{CO}_{2}$ injection for achieving accelerated $\mathrm{CO}_{2}$ dissolution has been studied by Leonenko and Keith [17]. Orr [14] and Bryant et al. [15] have also claimed that $\mathrm{CO}_{2}$-chasing water injection can expedite the process of residual trapping. Promising results have been obtained from both numerical simulations and feasibility analysis. The fundamental mechanism of accelerating $\mathrm{CO}_{2}$ dissolution by water injection is the enhanced convective mixing of $\mathrm{CO}_{2}$ and brine/water. Since WAG operation consists of repeated cycles of waterchasing $\mathrm{CO}_{2}$ injection, it is expected that the $\mathrm{CO}_{2}$ dissolution will be enhanced with the deployment of WAG.

\subsection{WAG setup and its modeling with GA-TOUGH2}

One complete cycle of $\mathrm{CO}_{2}$-water injection is identified as a WAG cycle. A complete WAG operation is constituted of a series of such basic WAG cycles. For simplicity of analysis, it is assumed that WAG cycles are identical to each other. 
A schematic of the considered WAG operation is shown in Figure 2, with red blocks and blue blocks representing $\mathrm{CO}_{2}$ injection and water injection respectively. The width of the blocks represents the duration of injection.

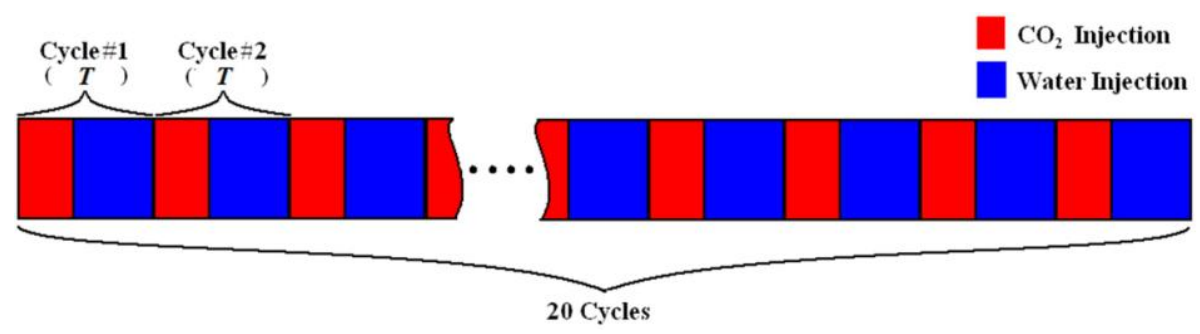

Fig 2: Schematic of the considered WAG operation [10]

A set of four basic variables determines a unique cycle pattern identified as: $\mathrm{CO}_{2}$ mass injection rate $I_{\mathrm{CO} 2}$, water mass injection rate $I_{\text {water }}$, WAG ratio $r_{W A G}$ (the ratio of injected $\mathrm{CO}_{2}$ mass to injected water mass per cycle), and cycle duration $T$. Assuming the duration of $\mathrm{CO}_{2}$ injection in one WAG cycle as $t_{C O 2}$, it can be expressed as Eq. 2.

$t_{\mathrm{CO} 2}=\frac{r_{W A G} \cdot I_{\text {water }} T}{r_{W A G} \cdot I_{\text {water }}+I_{C O 2}}$

Eq. 2 suggests that a WAG operation can be uniquely defined if the four basic variables are given. Optimization of these four independent variables becomes a four-dimensional design problem, which can be computationally very expensive. To make the optimization tractable, WAG cycle duration $T$ is assumed to be constant and is determined prior to optimization. With these simplifications, the number of independent variables that uniquely determines a WAG operation reduces by two. Since WAG cycle duration $T$ is pre-determined, any two variables from $I_{\mathrm{CO} 2}, I_{\text {water }}$, or $r_{W A G}$ can be picked as the basic design variables for the optimization of WAG operation, and there is no constraint or preference as to which of these two parameters should be chosen. Picking $I_{\mathrm{CO} 2}$ and $I_{\text {water }}$ as the two design variables, the remaining variable $r_{W A G}$ is determined by Eq. 3 .

$$
\begin{aligned}
r_{W A G} & =\frac{m_{\mathrm{CO} 2}}{m_{\text {water }}}=\frac{M_{\mathrm{CO} 2} / n}{I_{\text {water }} t_{\text {water }}}=\frac{M_{\mathrm{CO} 2}}{n I_{\text {water }}\left(T-M_{\mathrm{CO} 2} / n I_{\mathrm{CO} 2}\right)} \\
& =\frac{M_{\mathrm{CO} 2}}{I_{\text {water }}\left(n T-M_{\mathrm{CO} 2} / I_{\mathrm{CO} 2}\right)}=\frac{M_{\mathrm{CO} 2} I_{\mathrm{CO} 2}}{I_{\text {water }}\left(I_{\mathrm{CO}_{2}} n T-M_{\mathrm{CO} 2}\right)}
\end{aligned}
$$

In Eq. 3, $M_{\mathrm{CO} 2}$ is the total amount of $\mathrm{CO}_{2}$ to be sequestered and $n$ is the total number of WAG cycles.

Eq. 2 and Eq. 3 determine unique WAG patterns. Recalling that gaseous $\mathrm{CO}_{2}$ reaches the caprock relatively fast under buoyancy and then migrates underneath the caprock, it is the radial migration of gaseous $\mathrm{CO}_{2}$ that causes enormous land use as well as the leakage risk. Therefore, the saturation of gaseous phase $\mathrm{CO}_{2}$ (SG) directly underneath the caprock, originating from the injection well along the migration direction, should serve as an ideal indicator of storage efficiency. $\mathrm{SG}$ is the percentage of void space in the formation occupied by gaseous $\mathrm{CO}_{2}$; thus it varies from 0 to 1 . It becomes greater than zero when $\mathrm{CO}_{2}$ displacement of brine occurs and remains zero in $\mathrm{CO}_{2}$ free zones. Therefore, the maximum migration of in situ $\mathrm{CO}_{2}$ can be effectively determined by examining SG profile underneath the caprock. Additionally, cross-sectional SG contours can also indicate the migration and dissolution of in situ $\mathrm{CO}_{2}$.

\section{SAGCS simulation for Utsira formation}

The Sleipner project near the Norwegian coast at North Sea is probably the most well-known, important and successful saline aquifer geological carbon sequestration (SAGCS) demonstration so far. Starting from 1996, the Sleipner field in the North Sea has been the host of the world's first commercial SAGCS project. $\mathrm{CO}_{2}$ is captured from the gas mixture produced from a nearby deeper natural gas reservoir. Until today, approximately 1 million tons of supercritical $\mathrm{CO}_{2}$ has been sequestered annually. The Sleipner project has the most complete topographic description, industrial-scale injection amount, and long-term monitoring data. Nevertheless, great uncertainties still exist for accurate reservoir-scale simulation of the Sleipner project. Simulation and optimization studies of this project can provide helpful insights in understanding the transport behavior of in situ $\mathrm{CO}_{2}$ and the reservoir performance.

Utsira saline aquifer is the target formation for permanent carbon sequestration for the Sleipner SAGCS project. It is located at a depth of $800 \mathrm{~m}-1100 \mathrm{~m}$ from the seabed with thickness of about $200 \mathrm{~m}-250 \mathrm{~m}$. The injection site is located at the southern portion of Utsira formation. A $250 \mathrm{~m}-330 \mathrm{~m}$ thick shale layer known as the Nordland Formation serves as the caprock, and core testing has suggested its potential of bearing $\mathrm{CO}_{2}$ column of at least $100 \mathrm{~m}$ but perhaps up to $400 \mathrm{~m}$ (depending on the in situ conditions). It has been estimated that Utsira formation is highly stratified, consisting of sublayers with high-permeability sandstone and low-permeability shale. Figure 3 shows a $2 \mathrm{D}$ 
seismic image taken in 2008 revealing $\mathrm{CO}_{2}$ plume in Utsira formation [19]. Multiple layers can be distinctly identified from the seismic image.

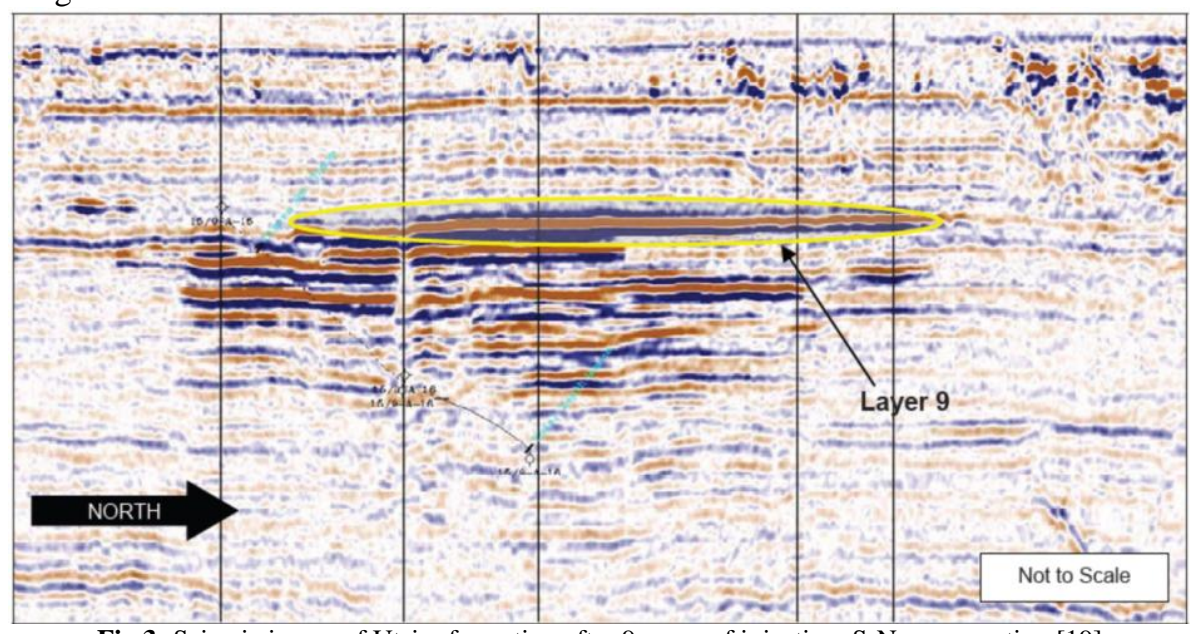

Fig 3: Seismic image of Utsira formation after 9-years of injection, S-N cross-section [19]

Two numerical models have been constructed for the study of Sleipner SAGCS project. The first model (Model \#1) is a generalized cylindrical layered model for estimating the overall migration of in situ $\mathrm{CO}_{2}$. The purpose of this simulation is to determine the secondary sealing effect and gain an overview of the plume migration within Utsira formation. The second model describes a total of $48 \mathrm{~km}^{2}$ area of detailed topmost sandstone layer (marked as Layer \#9 in Figure 3). Layer \#9 is of particular interest regarding the safety of the sequestration project, as it is the layer within which highest concentration of gaseous $\mathrm{CO}_{2}$ exists and most significant plume migration occurs. Detailed topography of Layer \#9 is described in Model \#2, making it a complicated 3D model. The detailed Layer \#9 model is introduced to investigate the effect of actual topography on in situ $\mathrm{CO}_{2}$ migration, while avoiding intensive computational effort associated with full 3D modeling and simulation of the entire Utsira formation. With satisfactory simulation results, WAG operation and its optimization is applied to both the models to "test" its feasibility for retarding in situ $\mathrm{CO}_{2}$ migration.

\subsection{Model \#1 - generalized model of stratified Utsira formation}

\subsubsection{Simulation and flux analysis for the Utsira formation}

Pre-injection geological survey has unveiled the layered structure of Utsira formation. The majority of Utsira formation can be identified as an 8-layered structure, however, one extra layer needs to be added to the structure near the injection site due to the existence of a sand wedge [20], [21], [22]. A cylindrical domain with nine alternating sandstone and shale layers is constructed. According to the seismic survey, it is assumed that all four shale layers have identical thickness of $5 \mathrm{~m}$, four shallower sandstone layers have identical thickness of $25 \mathrm{~m}$, and the bottom sandstone layer has a thickness of $60 \mathrm{~m}$. It adds up to a total $180 \mathrm{~m}$ thickness for the modeled Utsira formation. Lateral radius of the generalized cylindrical model reaches $100 \mathrm{~km}$, which is about the same as the actual extent of the southern part of Utsira formation. Following Audigane et al.'s suggestions [22], all sandstone layers possess identical and isotropic hydrogeological properties and so do the shale layers. Figure 4 shows the layered structure and computational mesh of the modeled Utsira formation as well as the location of $\mathrm{CO}_{2}$ injection. The permeability and porosity respectively are 3 Darcy and 0.42 for sand layer, and $10 \mathrm{mDarcy}$ and 0.1025 for shale layer. Temperature of $37^{\circ} \mathrm{C}$ and hydrostatic pressure of $11 \mathrm{MPa}$ are employed as the pre-injection conditions. van Genuchten-Mualem functions are used to describe both the relative permeability and capillary pressure. $\mathrm{CO}_{2}$ injection of $30 \mathrm{~kg} / \mathrm{s}$ is assigned as a point source at the middle of the bottom-most sand layer.

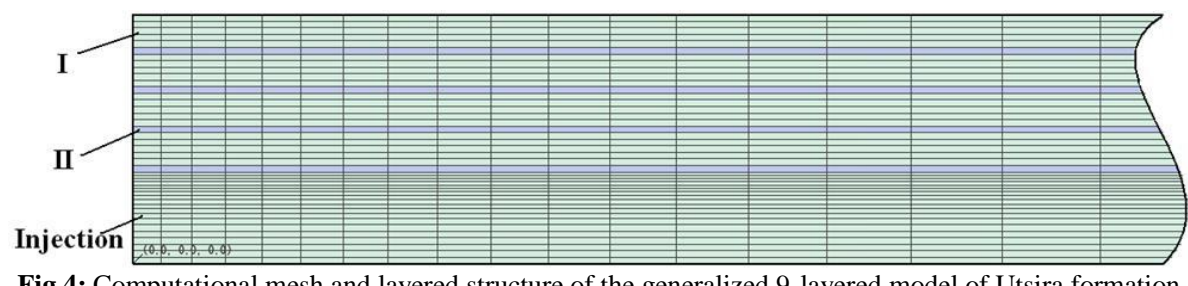

The simulation time is set at 14 years and $\mathrm{CO}_{2}$ plume profile is examined for each year. Figure 5 shows the crosssectional view of gaseous $\mathrm{CO}_{2}$ in the reservoir for 14 consecutive years since the inception of the injection. 


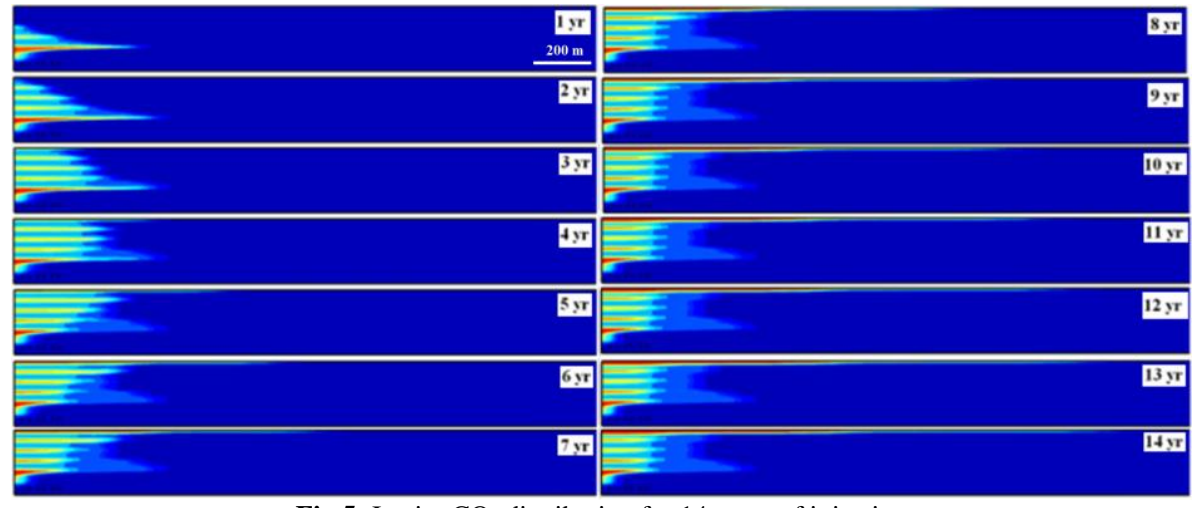

Fig 5: In-situ $\mathrm{CO}_{2}$ distribution for 14 years of injection

Results shown in Figure 5 provide evidence of strong secondary-sealing effect for the migration of in situ $\mathrm{CO}_{2}$. Driven by buoyancy, the injected $\mathrm{CO}_{2}$ first migrates upwards until it gets in contact with the first shale layer. Due to the low permeability and high capillary entry pressure, $\mathrm{CO}_{2}$ is confined by this shale layer and is forced to migrate radially. Simultaneously, $\mathrm{CO}_{2}$ concentration builds up beneath the shale layer and finally overcomes the capillary barrier after sustaining sufficient $\mathrm{CO}_{2}$ column height. The accumulation-penetration-breakthrough takes place each time the $\mathrm{CO}_{2}$ plume encounters a new shale layer and forms an upside-down pyramid shaped sub-plume as documented clearly by the first and second year plume shapes in Figure 5. Due to the secondary sealing effect, in situ $\mathrm{CO}_{2}$ has very limited contact with the caprock of Utsira formation by the third year of injection. The secondary-sealing mechanism also explains the increasing trend of $\mathrm{CO}_{2}$ accumulation rate in the topmost sandstone layer before it is stabilized at about 3000 days of injection, as shown in Figure 6. When breakthrough of capillary barrier first occurs, the pressure gradient just breaks the equilibrium state, resulting in relatively low upward mass flux to the overlying layer. However, as higher $\mathrm{CO}_{2}$ column accumulates, the pressure gradient gradually increases and leads to increasing breakthrough mass flux. As depicted in Figure 6, excellent agreement for the ten-year $\mathrm{CO}_{2}$ flux analysis for the topmost sandstone layer is obtained between our simulation and the seismic amplitudes analysis [23] suggesting the overall accuracy of our modeling despite some discrepancy at detailed level.

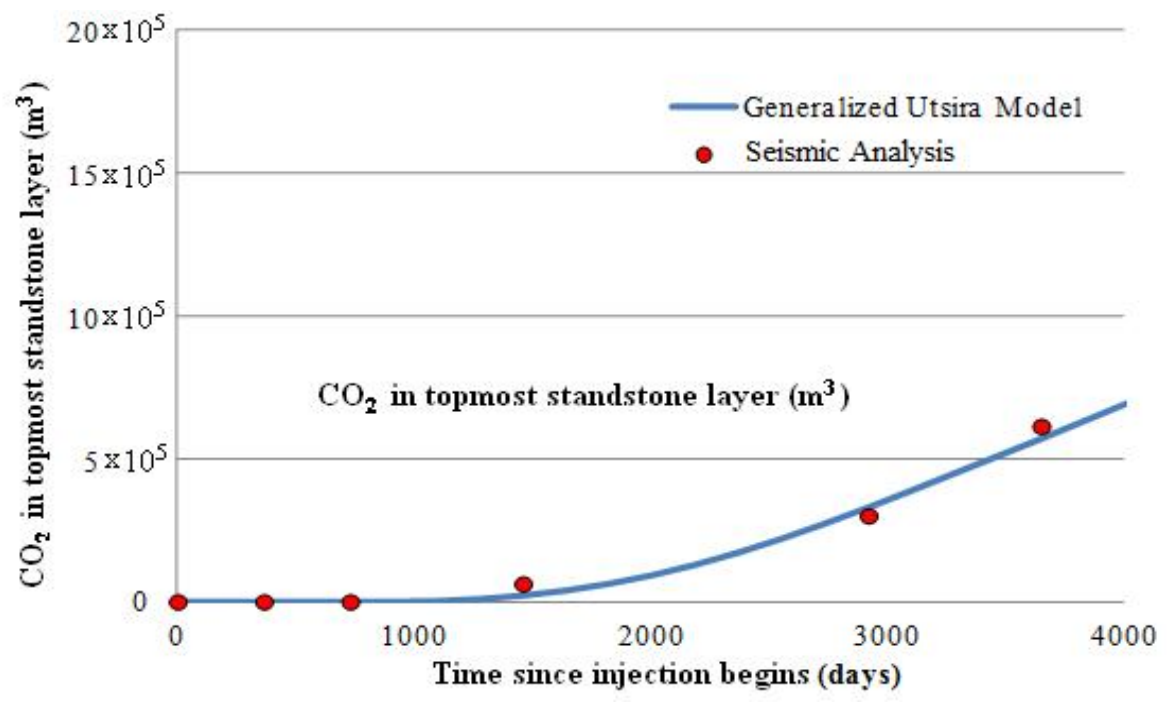

Fig 6: Gaseous $\mathrm{CO}_{2}$ accumulation in the topmost sandstone layer

\subsubsection{WAG operation and its optimization for the Utsira formation}

The WAG operation is employed to the cylindrical model of Utsira formation presented previously. All hydrogeological properties and numerical conditions used in the previous section are retained. The fitness function of the optimization, i.e. the criteria for evaluating the performance of WAG operation, is defined as the $\mathrm{CO}_{2}$ migration reduction with respect to that of conventional constant-gas-injection (CGI) operation normalized by the total amount of water injection, as described in Eq. 4. In Eq. 4, $R_{C G I}$ and $R_{W A G}$ are the maximum horizontal extent of in situ $\mathrm{CO}_{2}$ plume under CGI operation and under WAG operation respectively and $m_{\text {water }}$ is the total water injection associated with the WAG operation. This choice of fitness function arises from consideration of the economic feasibility of implementing the WAG operation, since the transportation and pumping of water is likely to consume additional energy and reduce the $\mathrm{CO}_{2}$ injectivity. However, previous investigations have suggested that the pressure elevation due to the water injection depends highly on the hydrogeological properties of the particular saline formation hosting the sequestration and the 
injection well orientation [10], [11]. When properly configured, the pressure elevation under WAG operation could be as small as $8 \%$ of the pre-injection reservoir pressure [10], [11]. It is obvious that a trade-off exists between the water consumption and the $\mathrm{CO}_{2}$ migration reduction. Therefore, it is clear that the WAG operation leading to the maximum value of the fitness function would provide the optimal balance between the plume migration reduction and the water requirement. It should be noted that the choice of fitness function is not unique, but does represent the key physical parameters of interest.

fitness $=\frac{R_{C G I}-R_{W A G}}{m_{\text {water }}}$

A 30-day WAG cycle duration is chosen considering the relatively thick formation. The WAG operation lasts for 5 years, during which 1 million tons of $\mathrm{CO}_{2}$ is injected annually. The optimization criterion is examined after 2, 3, and 5 years of WAG operation.

The values of design variables corresponding to the optimal WAG operation and the highest fitness function value are found as $I_{C O 2, \text { optimal }}=95.72 \mathrm{~kg} / \mathrm{s}, I_{\text {water, optimal }}=75.32 \mathrm{~kg} / \mathrm{s}, r_{W A G, \text { optimal }}=0.64$, and fitness $s_{\text {optimal }}=0.0251 \mathrm{~m} / 10^{3}$ tons of water. Correspondingly, the durations of $\mathrm{CO}_{2}$ and water injection in one WAG cycle can be calculated to be 10 and 20 days respectively. Identical WAG cycles are repeated 60 times to complete the entire 5-year operation. Figure 7 shows the schematic of the optimal WAG operation for the generalized Utsira formation model.

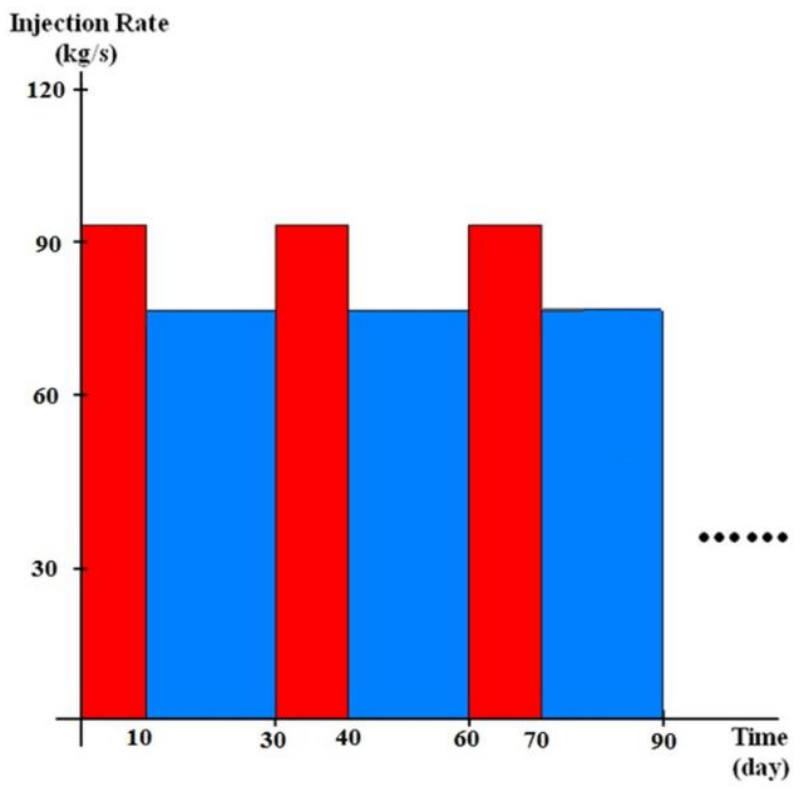

Fig 7: Schematic of optimized WAG operation for Utsira formation, red: $\mathrm{CO}_{2}$ injection, blue: water injection

Figure 8 shows the $\mathrm{CO}_{2}$ migration underneath the caprock at $2^{\text {nd }}, 3^{\text {rd }}$, and $5^{\text {th }}$ year for the optimized WAG and the conventional CGI operations. The reduction in radial $\mathrm{CO}_{2}$ migration is prominent with the WAG operation.

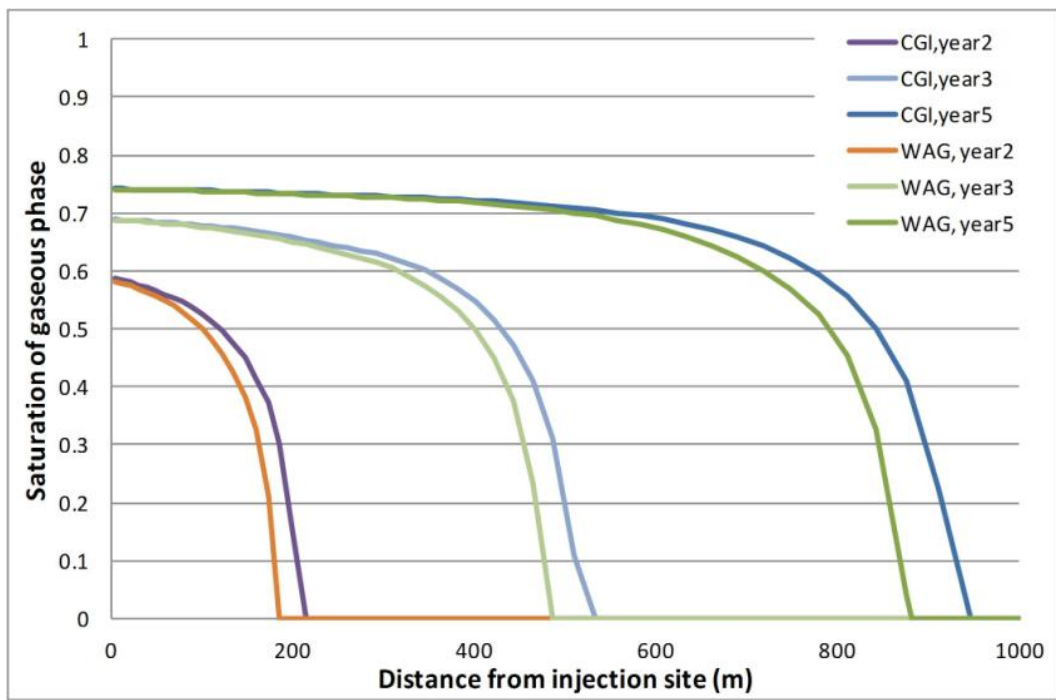

Fig 8: SG underneath the caprock at 2,3, and 5 years of injection showing plume reduction with optimized WAG operation for Utsira formation SAGCS 
Table 1 summarizes the benefits of adopting the optimal WAG operation for the generalized Utsira formation model. As seen from Figure 8 and Table 1, $\mathrm{CO}_{2}$ migration under the caprock in the generalized Utsira formation model has been reduced by the WAG operation. Time-elapse $\mathrm{CO}_{2}$ migration shown in Figure 8 provides the clear evidence that noticeable reduction in $\mathrm{CO}_{2}$ migration can be observed as early as 2 years after injection. More importantly, it can also be seen that migration reduction in later years tends to be greater than that in the earlier years, suggesting the development of greater reduction in $\mathrm{CO}_{2}$ migration as injection proceeds. Additionally, $\mathrm{CO}_{2}$ dissolution has been increased by about $7 \%$ of the total injected amount within 5 years. This is an encouraging result considering the decades-long life-span of SAGCS projects. Closer look at the in situ $\mathrm{CO}_{2}$ migration for conventional CGI operation (shown in Figure 9) and the optimal WAG operation (shown in Figure 10) provides the information of the effect of layered structure on conventional CGI and optimal WAG operation. Comparing Figure 9 and Figure 10 side by side, displacement of brine by $\mathrm{CO}_{2}$ in the lower sandstone layer becomes more stable under the optimal WAG operation. Therefore, storage efficiency increases under such scenario since more pore-space can now be occupied by supercritical $\mathrm{CO}_{2}$ and storage safety is improved due to the lowered concentration of supercritical $\mathrm{CO}_{2}$.

Table 1: Benefits of implementing the optimized WAG operation for Utsira formation SAGCS

\begin{tabular}{lll}
\hline CGI & $\mathrm{CO}_{2}$ Radial Migration & $946.7 \mathrm{~m}$ \\
WAG & Dissolution & $16.89 \%$ \\
& $\mathrm{CO}_{2}$ Radial Reduction & $65.2 \mathrm{~m}$ \\
& $\mathrm{CO}_{2}$ Radial Reduction Ratio & $6.89 \%$ \\
& $\mathrm{CO}_{2}$ Impact Area Reduction & $372,095 \mathrm{~m}^{2}$ \\
& $\mathrm{CO}_{2}$ Impact Area Reduction Ratio & $13.23 \%$ \\
& Total Water Injection Required & 1.5625 million tons annually \\
& $\mathrm{CO}_{2}$ Dissolution & $23.43 \%$ \\
\hline
\end{tabular}
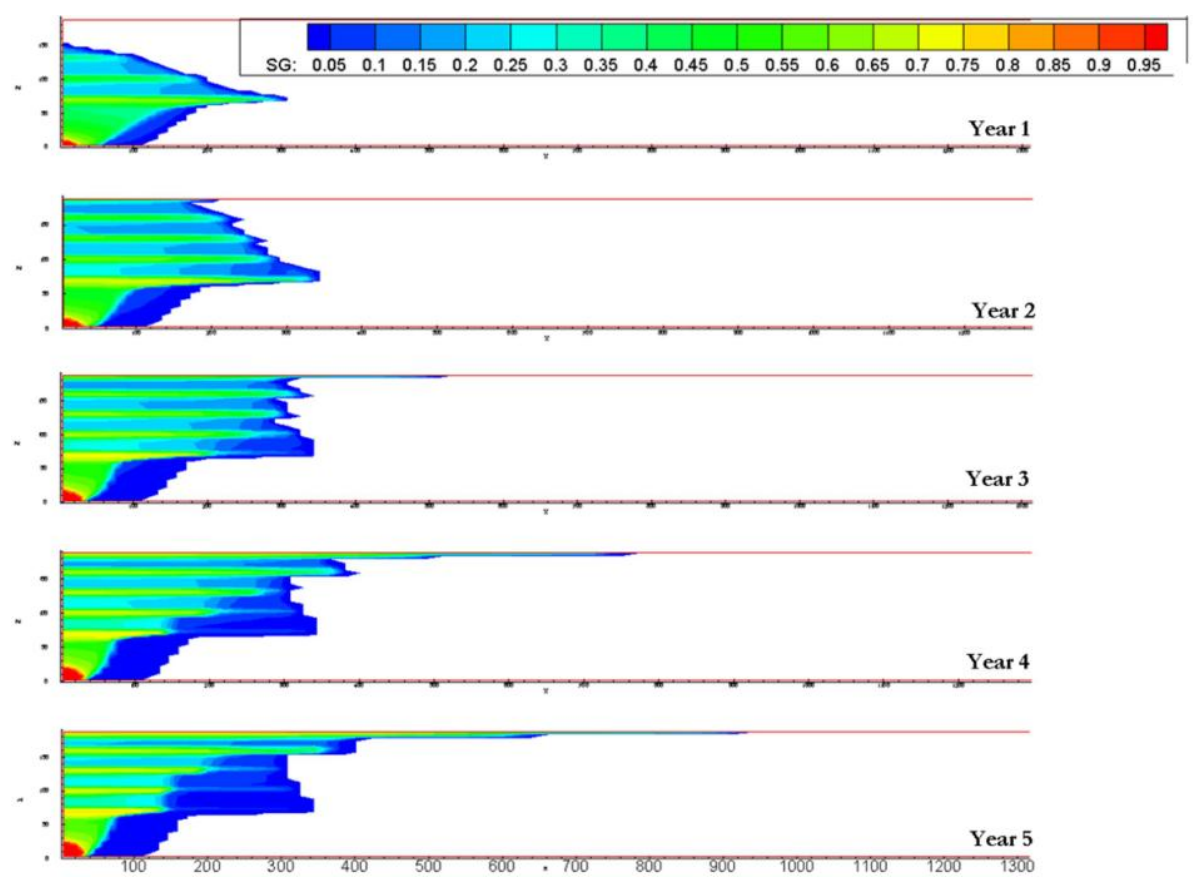

Fig 9: $\mathrm{CO}_{2}$ plume migration during the first 5 years of CGI operation for the Utsira formation 

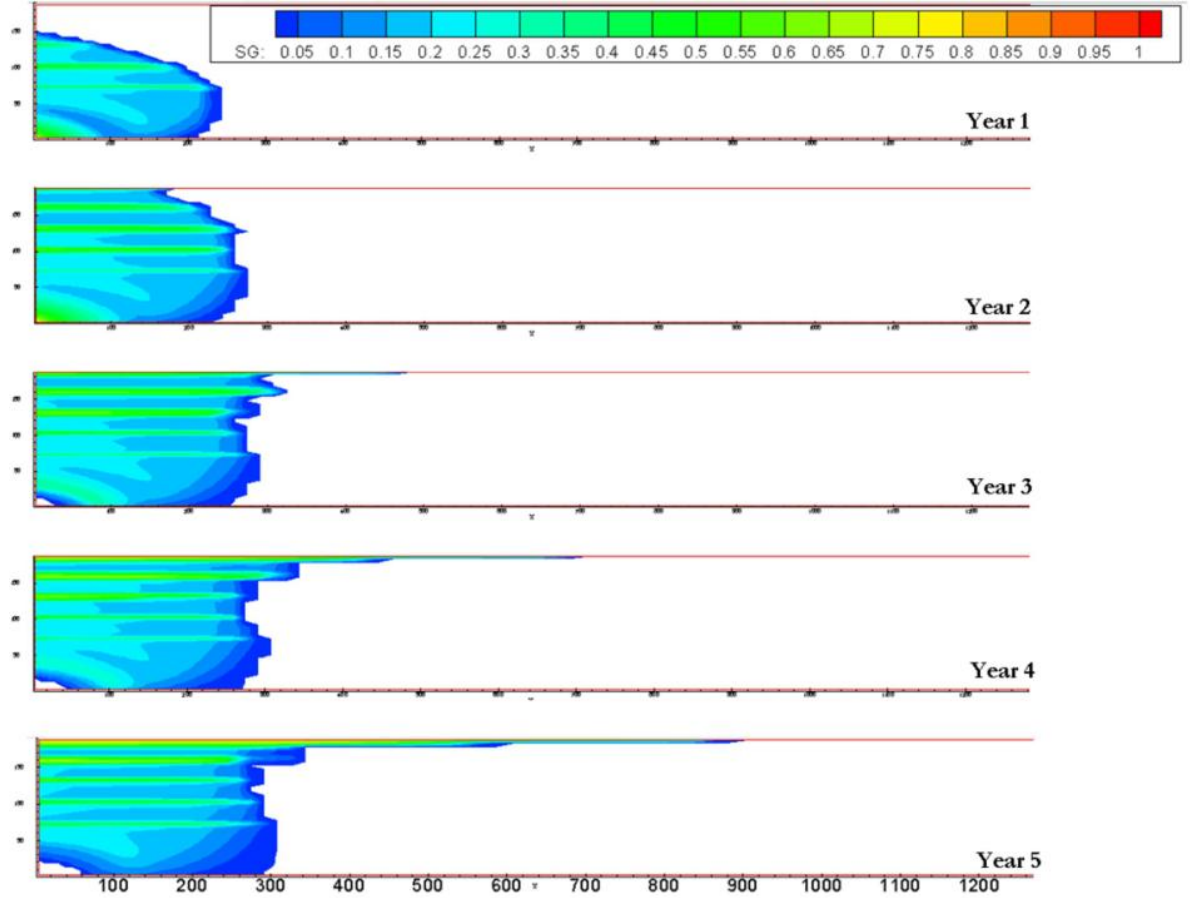

Fig 10: $\mathrm{CO}_{2}$ plume migration during the first 5 years of optimized WAG operation for the Utsira formation

\subsection{Model \#2 - detailed 3D model of Utsira Layer \#9 formation.}

\subsubsection{Simulation and plume history matching for $\mathrm{CO}_{2}$ plume within the Utsira layer \#9 formation}

In situ $\mathrm{CO}_{2}$ possesses strong potential to migrate upward due to buoyancy and accumulates under the caprock unless capillary barrier is compromised. The simulations using model \#1 have demonstrated that the accumulation of $\mathrm{CO}_{2}$ under the caprock occurs in a relatively short period compared to the entire life-span of a SAGCS project and it is a major concern for storage security. Therefore, it is critical for a SAGCS project to identify the accumulation of $\mathrm{CO}_{2}$ and its tendency of migration underneath the caprock. With such information available, precautionary treatments could be deployed to avoid potential leakage. The topmost sandstone layer of Utsira formation near the injection site, Layer \#9, is of most interest since it has the highest concentration of gaseous $\mathrm{CO}_{2}$ and has direct contact with the overlying caprock formation. Seismic survey has shown striking growth of $\mathrm{CO}_{2}$ accumulation in Layer \#9 between 1999 and 2006 as shown in Figure 11 [23].

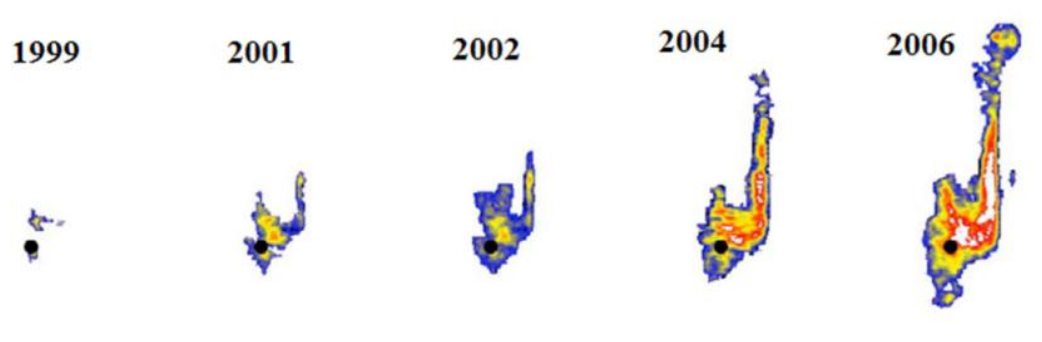

Fig 11: Amplitude maps of Layer \#9 from 1999 to 2008, Singh et al. [23]

The black dot in Figure 11 marks the location of the injection well, which is roughly $200 \mathrm{~m}$ under Layer \#9. Two distinct local $\mathrm{CO}_{2}$ accumulations appeared after about three years of injection (recall that injection began in 1996) indicating $\mathrm{CO}_{2}$ began to accumulate under the caprock. However, $\mathrm{CO}_{2}$ migration in Layer \#9 was not symmetric due to the topography of the caprock. The northward migration of initially impacted $\mathrm{CO}_{2}$, seen as the "body" of the plume in Figure 11, implies a local topographic dome; a prominent north-tending migration, seen as the "finger" of the plume in Figure 11, implies the spill of local structurally trapped $\mathrm{CO}_{2}$ along a north-tending topographic ridge. $\mathrm{CO}_{2}$ migration along the north-tending ridge was rather fast at about $1 \mathrm{~m} /$ day between 2001 and 2004 [24].

In order to examine the plume evolution within the topmost layer more closely, a 3D model of Utsira Layer \#9 is created with detailed topography. It should be noted that only Layer \#9, not the entire depth, is modeled because of the following considerations. To ensure the accurate capture of topographic effect on plume shaping, computational domain with considerable fine mesh resolution has to be modeled based on geological survey data. The computational effort and thus the feasibility of highly detailed model of the entire Utsira formation is very intensive and time consuming. 
Secondly, $\mathrm{CO}_{2}$ has to breakthrough several layers of relatively low permeability shale prior to reaching the topmost layer. While it is difficult to accurately quantify the breakthrough of gaseous $\mathrm{CO}_{2}$, the quantification of $\mathrm{CO}_{2}$ feeding into the topmost layer (Layer \#9) is rather reliable. Therefore, a model of only the topmost layer (Layer \#9) could provide an ideal platform to investigate the effect of various parameters such as topography on the shaping of $\mathrm{CO}_{2}$ plume.

A reservoir model with dimension of $1600 \mathrm{~m} \times 4900 \mathrm{~m}$ and varying thickness was constructed. It covers the portion of Utsira formation where the plume shown in Figure 11 resides. As mentioned earlier, the topography of this portion of Utsira formation is accurately modeled based on seismic geological survey data (provided by Zhu and Lu of the University of Indiana [25], [26]) with $50 \mathrm{~m} \times 50 \mathrm{~m}$ mesh resolution. Because only Layer \#9 is modeled, the thickness of computational domain varies from $3.5 \mathrm{~m}$ to $26.3 \mathrm{~m}$ with an average thickness of $11.3 \mathrm{~m}$. However to accurately capture the accumulation and upward and lateral movement of $\mathrm{CO}_{2}, 37$ layers are used along the thickness. The topmost layer and the bottom two layers are designated to represent the low permeability shale, while the 34 layers in the middle are assigned the properties of mudstone. In the 3D Layer \#9 model, permeability anisotropy is considered with west-east permeability of 2 Darcy, north-south permeability of 10 Darcy, and vertical permeability of $200 \mathrm{mDarcy}$. Detailed hydrogeological properties of the Layer \#9 model are summarized in Table A1. Overview of the Layer \#9 model is shown in Figure 12.

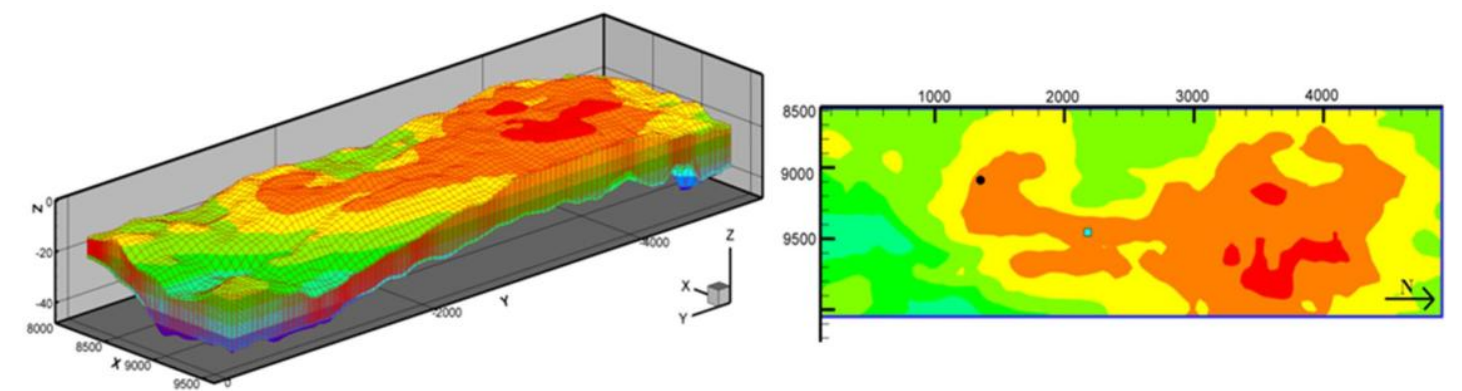

Fig 12: Overview and plan-view of the 3D Layer \#9 model of Utsira indicating feeder locations (black dot: main feeder; cyan square: secondary feeder)

It should be noted that for the 3D Layer \#9 model, the source of $\mathrm{CO}_{2}$ is identified as "feeder" but not "injector" to emphasize that $\mathrm{CO}_{2}$ is supplied from the lower aquifer through leakage pathways rather than by direct injection. Since the actual $\mathrm{CO}_{2}$ injector is located at about $200 \mathrm{~m}$ under Layer $\# 9$, information of injection rate recorded at the injector is not applicable for the $\mathrm{CO}_{2}$ feeders in Layer \#9 model. To determine the $\mathrm{CO}_{2}$ feeding rate to Layer \#9, seismic surveys of $\mathrm{CO}_{2}$ distribution are used to obtain its volume under in situ conditions, and then converted to mass flow rate. Information of $\mathrm{CO}_{2}$ accumulative mass provided by $\mathrm{Zhu}$ and $\mathrm{Lu}$ [25] as well as validated by Figure 6 is summarized in Table A2.

The significant north-tending plume finger is rather perplexing for regular pressure-gradient driven Darcy flow. Analysis suggests three possible explanations to the cause of prominent north-tending $\mathrm{CO}_{2}$ fingering along the ridge, which are: (1) significantly higher permeability applied to the ridge; (2) existence of north-south geological slope which enhances the buoyancy-drive migration along the ridge; and (3) existence of a secondary (or even multiple) $\mathrm{CO}_{2}$ pathway under the ridge. The hypothesis of significantly higher permeability at the ridge can be easily ruled out since no such evidence is obtained from the geological survey. It is still under debate whether geological slope should be considered when analyzing the $\mathrm{CO}_{2}$ migration in Utsira formation. Chadwick and Noy's work [24] has suggested two possible values of geological slope based on the seismic images of the cross-section of the Utsira formation, which are $8.2 \mathrm{~m} / \mathrm{km}$ and $5.8 \mathrm{~m} / \mathrm{km}$. The simulation time is set at nine years, which corresponds to the injection period of 1999 2008. $\mathrm{CO}_{2}$ plume migration at the topmost layer is examined for each year. Considering all the uncertainties mentioned above, a total of nine simulations are performed until a good history-matching can be obtained [27]. The final satisfactory history-matching of $\mathrm{CO}_{2}$ plume within Layer \#9 is shown as Figure 13.
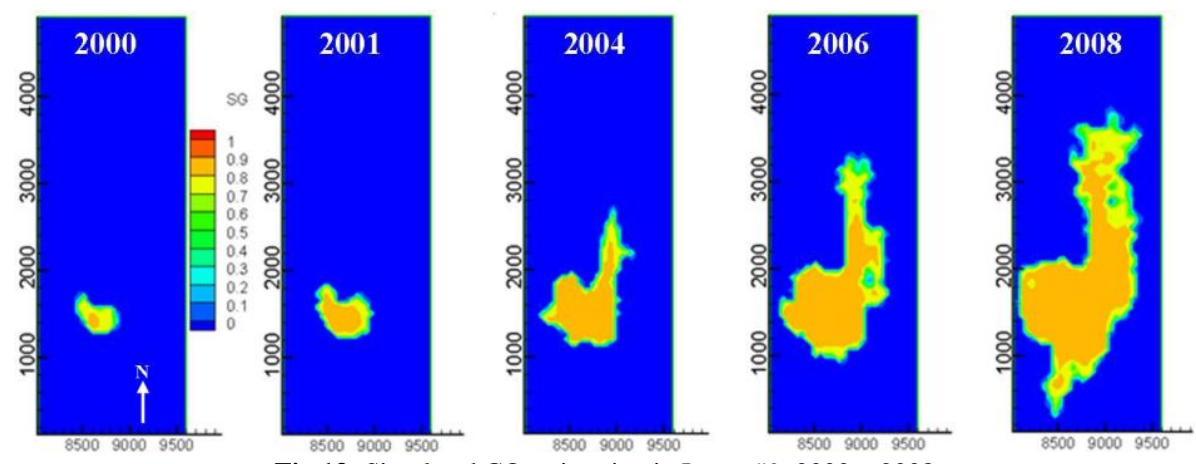

Fig 13: Simulated $\mathrm{CO}_{2}$ migration in Layer \#9, $2000 \sim 2008$ 
Both the 2D generalized Utsira formation model and the 3D detailed Utsira Layer \#9 model have generated satisfactory simulation results as seen by history-matching. In summary, five major conclusions can be made as follows. First, the simulations show that the permeability anisotropy should be accurately modeled. Vertical-to-horizontal anisotropy (vertical permeability to W-E permeability) close to $1: 10$ is needed to accurately capture the upward migration of $\mathrm{CO}_{2}$. Horizontal anisotropy (W-E permeability to N-S permeability) of 2:10 is needed to capture the northern $\mathrm{spill}_{\text {of }} \mathrm{CO}_{2}$ into the north-tending ridge. Secondly, a secondary feeder is likely to exist directly under the north-tending ridge to generate sufficient plume migration along the ridge. It suggests multiple pathways for $\mathrm{CO}_{2}$ breakthrough from the lower aquifer structure. Thirdly, the fact that injection gas being $\mathrm{CO}_{2}$-methane mixture is very important in modeling since the presence of $2 \%$ methane enhances the buoyancy. Fourthly, it is critical that time-dependent feeding of $\mathrm{CO}_{2}$ is modeled. This is consistent with the behavior of $\mathrm{CO}_{2}$ path flow breaking the capillary pressure barrier. And finally, the existence of geological slope should be ruled out due to the cause of significant over-spill of $\mathrm{CO}_{2}$ to the north.

\subsubsection{WAG operation and its optimization for Utsira Layer \#9 model}

The topmost sandstone layer (Layer \#9) of Utsira formation as presented in the previous section can serve as another excellent candidate for the investigation of WAG operation due to its well-understood hydrogeological properties. As a quick assessment, a cylindrical domain with the average thickness of Utsira Layer \#9 is modeled, which possesses identical characteristics of the 3D Utsira Layer \#9 model except for the absence of detailed topography. Although topographical details could be important in determining the accurate migration of in situ $\mathrm{CO}_{2}$, such a simplification without compromising accuracy is necessary for analyzing the effectiveness of WAG operation on $\mathrm{CO}_{2}$ migration without incurring excessive computational cost.

The geometric and hydrogeological characteristics of the simplified Utsira Layer \#9 model can be summarized as follows. We consider a cylindrical domain with thickness of $35 \mathrm{~m}$ with horizontal flat caprock. All hydrogeological properties are retained from the detailed 3D Utsira Layer \#9 model described previously, the most important being the horizontal-to-vertical permeability ratio of 10. CGI operation with nine-year average $\mathrm{CO}_{2}$ injection rate of $2.7 \mathrm{~kg} / \mathrm{s}$ is considered as the baseline case for comparison. Due to the relatively small thickness of the formation, three values of cycle duration, namely 30-day, 15-day, and 5-day are considered for the optimization. It turned out that only the case with 5-day cycle duration led to significant migration reduction for the Layer \#9 model. Therefore, all results given below are for the optimal WAG operation with 5-day cycle duration. The effect of cycle duration on the performance of WAG operation is discussed after the results.

The values of design variables corresponding to optimal WAG operation and the highest fitness function value are found as $I_{C O 2, \text { optimal }}=11.56 \mathrm{~kg} / \mathrm{s}, I_{\text {water,optimal }}=7.62 \mathrm{~kg} / \mathrm{s}, r_{W A G, \text { optimal }}=0.646$, and fitness optimal $=0.506 \mathrm{~m} / 10^{3}$ tons of water. Correspondingly, the durations of $\mathrm{CO}_{2}$ and water injection in one WAG cycle can be calculated to be 11 and 19 days respectively. Identical WAG cycles are repeated 24 times to complete a 2-year operation. Figure 14 shows the schematic of optimal WAG operation for the simplified Utsira Layer \#9 model with 5-day WAG cycle duration.

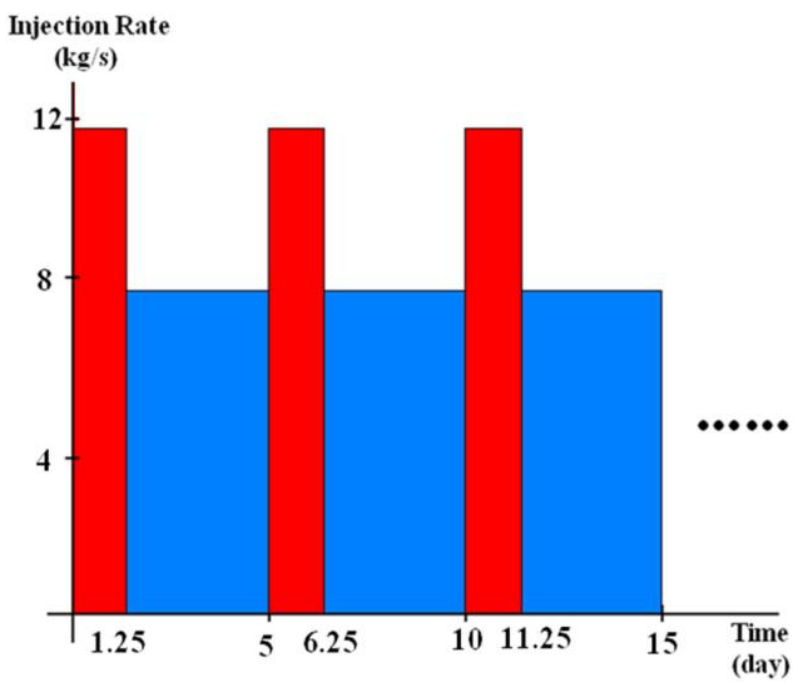

Fig 14: Schematic of the optimal WAG operation for Utsira Layer \#9 model, red: $\mathrm{CO}_{2}$ injection, blue: water injection

Figure 15 shows the $\mathrm{CO}_{2}$ migration underneath the caprock after two years of conventional CGI and optimized WAG operation. 


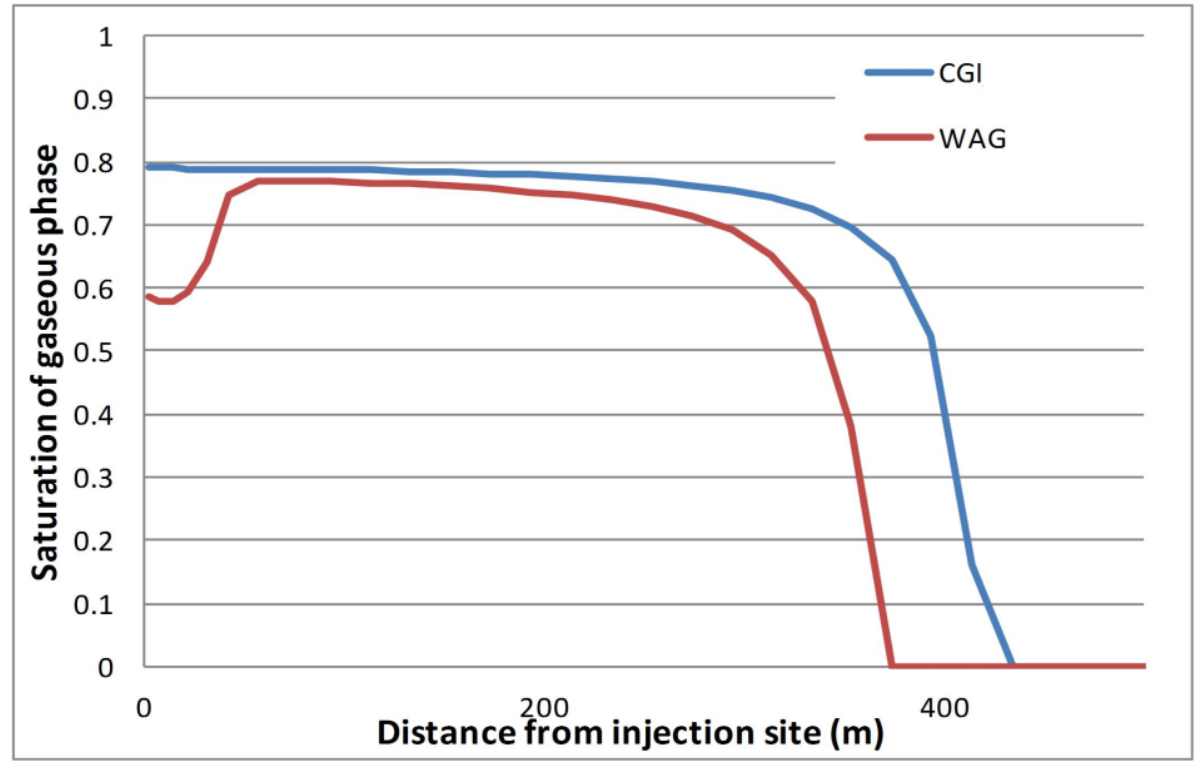

Fig 15: SG underneath the caprock showing plume reduction with optimized WAG injection for Utsira Layer \#9 model

Table 2 summarizes the benefits of adopting the optimized WAG injection for the Utsira Layer \#9 model.

Table 2: Benefits of optimized WAG operation for the Utsira Layer\#9 model

$\begin{array}{lll}\text { CGI } & \mathrm{CO}_{2} \text { Radial Migration } & 423 \mathrm{~m} \\ \text { WAG } & \text { Dissolution } & 8.97 \% \\ & \mathrm{CO}_{2} \text { Radial Reduction } & 49 \mathrm{~m} \\ & \mathrm{CO}_{2} \text { Radial Reduction Ratio } & 11.58 \% \\ & \mathrm{CO}_{2} \text { Impact Area Reduction } & 122689 \mathrm{~m}^{2} \\ \mathrm{CO}_{2} \text { Impact Area Reduction Ratio } & 21.83 \% \\ & \mathrm{Total}^{2} \text { Water Injection Required } & 231916 \text { tons } \\ & \mathrm{CO}_{2} \text { Dissolution } & 23.02 \% \\ & \end{array}$

As seen from Figure 15 and Table 2, significant reduction in $\mathrm{CO}_{2}$ migration has been achieved after only two years of WAG operation. Additionally, $\mathrm{CO}_{2}$ dissolution is also significantly enhanced from about $9 \%$ to $23 \%$ of the total injected $\mathrm{CO}_{2}$. More importantly, the results reveal the strong relationship between WAG cycle duration and the reservoir thickness regarding the performance of WAG operation. Surprisingly our simulation results show that the 30day cycle WAG operation actually "enhances" (not "reduces") the lateral migration of the $\mathrm{CO}_{2}$ plume. Such a situation can be slightly mitigated when the 15-day WAG cycle duration is applied; however, no noticeable migration reduction is achieved. Considering several cases of WAG operation not reported here, it appears that the aquifer thickness and WAG cycle duration are critical factors affecting the performance of a WAG operation. When the aquifer is thin, it takes less time for the $\mathrm{CO}_{2}$ to reach the caprock. The assumption of treating alternative water and $\mathrm{CO}_{2}$ slugs as quasimixture is only valid when injected $\mathrm{CO}_{2}$ interacts with the chasing water before it reaches the caprock. Failing to fulfill this requirement leads to poor WAG performance. It is the reservoir thickness and WAG cycle duration that determine the validity of quasi-mixture assumption for a given aquifer. Longer WAG cycle duration requires larger reservoir thickness and vice-versa. Our simulations show that minimum reservoir thickness may exist for a given WAG cycle duration under which the quasi-mixture assumption is valid and vice-versa. This minimum thickness requirement may ultimately determine the technical feasibility of WAG operation for an aquifer for achieving any reduction in $\mathrm{CO}_{2}$ migration. Following this rationale, the success of WAG operation with 5-day cycle duration and its failure with the 15day and 30-day cycle durations can be explained for Utsira Layer \#9 model. This also implies that the $\mathrm{CO}_{2}$ injected at the bottom of Layer \#9 reaches the caprock between 5 to 30 days (more likely in approximately 15 days since minor reduction in plume can be observed in this case) with the given reservoir hydrogeological properties and injection parameters.

With the optimization of WAG operation for the Sleipner SAGCS project, one can draw the conclusion that the WAG operation certainly holds technical promise in retarding the spread of gaseous $\mathrm{CO}_{2}$ in actual large scale saline aquifers such as the Utsira formation. It is also obvious from the results that the timeframe of in situ $\mathrm{CO}_{2}$-water mixing versus the chosen WAG cycle duration are important considerations that must be carefully determined in assuring the improved reservoir performance due to implementation of WAG operation. Various geological factors of the formation, such as geological slope and reservoir thickness could contribute to insufficient mixing and thus compromise the performance of WAG operation. Therefore the operational parameters of WAG operation should be designed on a caseby-case basis for achieving the optimal performance. 
Table A1: Hydrogeological properties for the Utsira Layer \#9 model

\begin{tabular}{ll}
\hline Temperature & $33^{\circ} \mathrm{C}$ \\
Pressure & $8.6 \mathrm{MPa}$ \\
Total Utsira Formation Area & $26100 \mathrm{~km}^{2}$ \\
Total Utsira Formation Thickness & $50 \mathrm{~m} \sim 300 \mathrm{~m}$ \\
Layer\#9 Area & $1600 \mathrm{~m} \times 4900 \mathrm{~m}$ \\
Layer\#9 Thickness & $3.5 \mathrm{~m} \sim 26.3 \mathrm{~m}$ \\
Shale Permeability & W-E: $0.001 \mathrm{mDarcy}, \mathrm{N}-\mathrm{S}: 0.001 \mathrm{mDarcy}$, Vertical: $0.0001 \mathrm{mDarcy}$ \\
Mudstone Permeability & W-E: 2 Darcy, N-S: 10 Darcy, Vertical: 200 mDarcy \\
Utsira Porosity (shale/mudstone) & $35.7 \%$ \\
Residual CO ${ }_{2}$ Saturation & 0.02 \\
Residual Brine Saturation & 0.11 \\
Relative Permeability Type & Corey/van Genuchten- Mualem \\
Capillary Pressure & None \\
Porewater Salinity & $3.3 \%$ \\
North-south Geological Slope & $8.2 \mathrm{~m} / \mathrm{km}, 5.8 \mathrm{~m} / \mathrm{km}$ \\
$\mathrm{CO}_{2}$ Feeder Location & Main feeder: W-E: $516 \mathrm{~m}, \mathrm{~N}-\mathrm{S}: 1210 \mathrm{~m}$, bottom mudstone \\
& Secondary feeder: W-E: $925 \mathrm{~m}, \mathrm{~N}-\mathrm{S}: 2250 \mathrm{~m}$, bottom mudstone \\
\hline
\end{tabular}

Table A2: Accumulative $\mathrm{CO}_{2}$ mass in Layer \#9, 1999-2008

\begin{tabular}{llll}
\hline Year & Accumulative Mass $(\mathrm{kg})$ & Yearly Feeding Mass $(\mathrm{kg})$ & Feeding Rate $(\mathrm{kg} / \mathrm{s})$ \\
\hline 1999 & 0.00 & 0.00 & 0.00 \\
2000 & $1.82 \times 10^{7}$ & $1.82 \times 10^{7}$ & 0.577 \\
2001 & $5.52 \times 10^{7}$ & $3.70 \times 10^{7}$ & 1.17 \\
2002 & $9.49 \times 10^{7}$ & $3.97 \times 10^{7}$ & 1.26 \\
2003 & $1.45 \times 10^{8}$ & $5.01 \times 10^{7}$ & 1.59 \\
2004 & $2.13 \times 10^{8}$ & $6.80 \times 10^{7}$ & 2.16 \\
2005 & $3.07 \times 10^{8}$ & $9.40 \times 10^{7}$ & 2.98 \\
2006 & $4.34 \times 10^{8}$ & $1.27 \times 10^{8}$ & 4.03 \\
2007 & $6.03 \times 10^{8}$ & $1.69 \times 10^{8}$ & 5.36 \\
2008 & $8.20 \times 10^{8}$ & $2.17 \times 10^{8}$ & 6.88 \\
\hline
\end{tabular}

\section{Concluding remarks}

Using the simulation-optimization integrated code GA-TOUGH2, excellent history-matching has been achieved for the Sleipner SAGCS project, and the feasibility and technical benefits of adopting water-alternating-gas (WAG) injection technique have been investigated. Encouraging results have been obtained which suggest that WAG operation holds the potential of improving the storage efficiency while keeping minimal energy penalty due to water injection. For better understanding of WAG injection technique, more complex optimization studies should be performed to address a broader set of optimization problems such as non-uniform WAG injection and maximization of $\mathrm{CO}_{2}$ dissolution and residual trapping. Nevertheless, GA-TOUGH2 has been proven to be a computationally accurate and robust platform to address various optimization problems related to geological carbon sequestration.

\section{Acknowledgement}

Financial support for this work was provided by the Consortium for Clean Coal Utilization (CCCU) at Washington University in St. Louis.

\section{References}

[1] US Department of Energy.: 2010 carbon sequestration atlas of the United States and Canada, 3rd edition, (2010).

[2] H. Class, A. Ebigbo, R. Helmig, H.K. Dahle, J.M. Nordbotten, M.A. Celia, et al., A benchmark study on problems related to CO 2 storage in geologic formations, Computational Geosciences 13(4) (2009) 409-434.

[3] M. Bickle, A. Chadwick, H.E. Huppert, M. Hallworth, S. Lyle, Modeling carbon dioxide accumulation at Sleipner: implications for underground carbon storage, Earth and Planetary Science Letters 255(1-2) (2007) 164-176.

[4] R.A. Chadwick, P. Zweigel, U. Gregersen, G.A. Kirby, S. Holloway, P.N. Johannessen, geological reservoir characterization of a CO 2 storage site: the Utsira sand, Sleipner, northern North Sea, Energy 29 (2004) 9-10.

[5] K. Pruess, TOUGH2: A general numerical simulator for multiphase fluid and heat flow. Lawrence Berkeley Laboratory Report LBL-29400, Berkeley, California, (1991). 
[6] K. Pruess, the TOUGH codes - a family of simulation tools for multiphase flow and transport processes in permeable media, Vadose Zone Journal 3 (2004) 738-746.

[7] K. Pruess, C. Oldenburg, G. Moridis, TOUGH2 User's Guide, Version 2.0 (revised), Lawrence Berkeley Laboratory Report LBL-43134, Berkeley, California, (2011).

[8] Genetic algorithm, Wikipedia website, http://en.wikipedia.org/wiki/Genetic_algorithm, last access: July 8, 2013.

[9] D.E. Goldberg, Genetic algorithms in search, optimization \& machine learning, Addison-Wesley, (1989).

[10] Z. Zhang, R.K. Agarwal, Numerical simulation and optimization of $\mathrm{CO}_{2}$ Sequestration in saline aquifers for vertical and horizontal well injection, Computational Geosciences 16 (4) (2012) 891-899.

[11] Z. Zhang, R.K. Agarwal, Numerical simulation and optimization of $\mathrm{CO}_{2}$ sequestration in saline aquifers for enhanced storage capacity and secured sequestration, International Journal of Energy and Environment 4 (3) (2013) 387-398.

[12] Z. Zhang, R.K. Agarwal, Numerical simulation and optimization of $\mathrm{CO}_{2}$ sequestration in saline aquifers, Computers \& Fluids 80 (2013) 7987.

[13] H. Tchelepi, L. Durlofsky, K. Aziz, A Numerical simulation framework for the design, management and optimization of $\mathrm{CO}_{2}$ sequestration in subsurface formations, Global Climate and Energy Project (GCEP) Report, Stanford, (2009).

[14] L. Orr, Carbon capture and sequestration: where do we stand, Presentation at NAE/AAES Convocation, Washington DC, and 19 April, 2010?

[15] S.L. Bryant, S. Lakshminarasimhan, G.A. Pope, Buoyancy-dominated multi-phase flow and its effect on geological sequestration of CO, Society of Petroleum Engineer Journal 13 (4) (2008) 447-454.

[16] S. Taku Ide, K. Jessen, F.M. Orr, Storage of $\mathrm{CO}_{2}$ in saline aquifers: effects of gravity, viscous, and capillary forces on amount and timing of trapping, Intentional Journal of Greenhouse Gas Control 1 (4) (2007) 481-491.

[17] Y. Leonenko, D.W. Keith, Reservoir engineering to accelerate the dissolution of $\mathrm{CO}_{2}$ stored in aquifers, Environmental Science \& Technology 42 (2008) 2742-2747.

[18] H. Hassanzadeh, M. Pooladi-Darvish, D.W. Keith, Accelerating $\mathrm{CO}_{2}$ Dissolution in saline aquifers for geological storage - mechanistic and sensitivity studies, Energy and Fuels 23 (2009) 3328-3336.

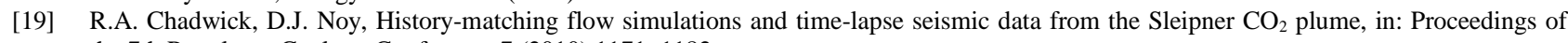
the 7th Petroleum Geology Conference 7 (2010) 1171-1182.

[20] R. Arts, O. Eiken, R.A. Chadwick, P. Zweigel, L. van der Meer, B. Zinszner, Monitoring of $\mathrm{CO}_{2}$ injected at Sleipner using time-lapse seismic data, Energy 29 (2004) 9-10.

[21] R. Arts, R.A. Chadwick, O. Eiken, S. Thibeau, S. Nooner, Ten years' experience of monitoring $\mathrm{CO}_{2}$ injection in the Utsira sand at Sleipner, offshore Norway, First Break 26 (2008) 65-72.

[22] P. Audigane, I. Gaus, I. Czernichowski-Lauriol, K. Pruess, T. Xu, Two-dimensional reactive transport modeling of $\mathrm{CO}_{2}$ injection in a saline aquifer at the Sleipner site, American Journal of Science 307 (2007) 974-1008.

[23] V. Singh, A. Cavanagh, H. Hansen, B. Nazarian, M. Iding, P. Ringrose, Reservoir modeling of $\mathrm{CO}_{2}$ plume behavior calibrated against monitoring data from Sleipner, Norway, Society of Petroleum Engineer Annual Technical Conference and Exhibit, Florence, Italy, (2010).

[24] R.A. Chadwick, R, Arts, O. Eiken, G.A. Kirby, E. Lindberg, P. Zweigel, 4D seismic imaging of an injected $\mathrm{CO}_{2}$ plume at the Sleipner field, Central North Sea, Geological Society of London Memoirs 29 (2004) 311-320.

[25] C. Zhu, P. Lu, Personal Communication, Department of Geological Sciences, University of Indiana (2012).

[26] C. Zhu, $\mathrm{CO}_{2}$-water-rock interaction in geological carbon sequestration, seminar presentation at Washington University in St. Louis (2011).

[27] Z. Zhang, R.K. Agarwal, Numerical simulation of geological carbon sequestration in saline aquifers, three case studies, in: Proceedings of 12th Annual Conference on Carbon Capture Utilization \& Sequestration, Pittsburgh, US (2013). 